\title{
Targeting phosphatidylinositol-3-kinase pathway for the treatment of Philadelphia- negative myeloproliferative neoplasms
}

\author{
Ruchi Pandey ${ }^{1,2}$ and Reuben Kapur ${ }^{1,2,3,4^{*}}$
}

\begin{abstract}
Myeloproliferative neoplasms (MPN) are a diverse group of chronic hematological disorders that involve unregulated clonal proliferation of white blood cells. Sevearl of them are associated with mutations in receptor tyrosine kinases or cytokine receptor associated tyrosine kinases rendering them independent of cytokine-mediated regulation. Classically they have been broadly divided into BCR-ABL1 fusion + ve (Ph + ve) or -ve (Ph-ve) MPNs. Identification of BCRABL1 tyrosine kinase as a driver of chronic myeloid leukemia (CML) and successful application of small molecule inhibitors of the tyrosine kinases in the clinic have triggered the search for kinase dependent pathways in other Ph-ve MPNs. In the past few years, identification of mutations in JAK2 associated with a majority of MPNs raised the hopes for similar success with specific targeting of JAK2. However, targeting JAK2 kinase activity has met with limited success. Subsequently, mutations in genes other than JAK2 have been identified. These mutations specifically associate with certain MPNs and can drive cytokine independent growth. Therefore, targeting alternate molecules and pathways may be more successful in management of MPNs. Among other pathways, phosphatidylinositol -3 kinase (PI3K) has emerged as a promising target as different cell surface receptor induced signaling pathways converge on the PI3K signaling axis to regulate cell metabolism, growth, proliferation, and survival. Herein, we will review the clinically relevant inhibitors of the PI3K pathway that have been evaluated or hold promise for the treatment of Ph-ve MPNs.
\end{abstract}

Keywords: PI3K inhibitors, myeloproliferative neoplasms, JAK2, Mastocytosis, Chronic leukemia

\section{Introduction}

The term 'myeloproliferative disorders' has historically been applied to a group of four hematological diseases - 1) polycythemia vera (PV), 2) essential thrombocythemia (ET), 3) primary myelofibrosis (PMF) and 4) chronic myeloid leukemia (CML). This grouping was based on some of the clinical and biological similarities in patients due to clonal proliferation of hematopoietic progenitor cells and excessive production of blood cells of different lineages. With a better understanding of the molecular events underlying these malignancies, the World Health Organization (WHO) has reclassified them on the basis of histology, translocations and mutations in protein tyrosine

\footnotetext{
* Correspondence: rkapur@iupui.edu

'Department of Pediatrics, Herman B Wells Center for Pediatric Research,

Indiana University School of Medicine, Indianapolis, IN 46202, USA

${ }^{2}$ Department of Microbiology and Immunology, Indiana University School of

Medicine, Indianapolis, IN 46202, USA

Full list of author information is available at the end of the article
}

kinases $[1,2]$. These have helped in diagnosis and consequent treatment decisions. Proliferative disorders associated with myeloid cells including the granulocytic, monocytic/ macrophage, erythroid, megakaryocytic, and mast cells have been grouped under 5 broad categories: (1) myeloproliferative neoplasms (MPN), (2) myeloid and lymphoid neoplasms associated with eosinophilia and abnormalities of platelet derived growth factor receptor (PDGFR) or fibroblast growth factor receptor (FGFR), (3) myelodysplastic/ myeloproliferative neoplasms (MDS/MPN), (4) myelodysplastic syndrome (MDS) and, (5) Acute myeloid leukemia and related neoplasms. The term 'myeloproliferative neoplasms' has replaced the older 'myeloproliferative disorders'. In addition to the four classical MPNs, PV, ET, PMF and $\mathrm{CML}(\mathrm{Ph}+\mathrm{ve})$, this group now also includes chronic neutrophilic leukemia (CNL), chronic eosinophilic leukemia not otherwise specified (CEL-NOS), mastocytosis and unclassifiable myeloproliferative neoplasms. For the purpose 
of this review we will focus on the Ph -ve MPNs as defined under the first category of WHO classification since others have been reviewed elsewhere [3, 4].

As per the estimates for 2008-2010, there were 44-57 and 38-57 PV and ET patients per 100,000 people respectively, while 4-6 PMF patients per 100,000 people in the United States [5]. MF can be primary or develop subsequent to PV/ET. Though its prevalence rate is low, it is the most disabling of the MPNs. No reliable estimates are available for the prevalence rate of mastocytosis, CNL and CEL. The chronic nature of MPNs, absence of a defined therapeutic regimen and potential for transformation to acute myeloid leukemia makes them a challenge. Until a few years back, there was no drug that was approved by Food and Drug Administration (FDA) for the treatment of MPN. Therefore, the treatment options for these patients were mostly empirical [6]. A kinase dependent oncogenic pathway essential for the survival of leukemic cells was identified in chronic myeloid leukemia (CML). The inhibition of the BCR-ABL1 kinase led to significant enhancement in the survival of CML patients [7]. These results along with other studies have contributed to the concept of 'oncogene addiction'. It is believed that cancer cells are addicted to the oncogene and targeting of the crucial oncogenes/pathways can lead to elimination of cancer cells. However, results from the clinic have demonstrated that cancer cells can acquire additional mutations and activate compensatory pathways that eventually lead to drug resistance and disease relapse [8].

\section{Genetic basis of MPNs}

Discovery of JAK2 $2^{\mathrm{V} 617 \mathrm{~F}}$ mutation in a majority of Ph-ve MPN patients and the ability of this mutant protein to recapitulate a MPN phenotype in experimental models has been a turning point in our understanding of classical Ph-ve MPNs [9-11]. It established a genetic basis for the classical Ph-ve MPNs. In addition to becoming an integral part of diagnosis, it has also opened up the field for selective targeting of the kinase pathway in treatment of Ph-ve MPNs. Since then several additional mutations have been identified that specifically associate with different myeloid neoplasms [12, 13]. These include components of the cytokine signaling, regulators of the chromatin structure and RNA splicing in addition to cytogenetic abnormalities with uniparental disomy of chromosome 9p being the most frequent ( 35\%) aberration. The driver mutations conferring a clonal proliferative advantage arise in the adult hematopoietic stem cell and early progenitor compartments. Acquisition of a combination of mutations is required for progression from the chronic phase to blast transformation [14, 15]. The number of mutations can range from 1 to 5 or more with or without abnormalities in the karyotype. Such heterogeneity in MPN patients indicates a complex evolutionary mechanism for the disease development. In addition to directing the course of disease progression, the combination of mutations also determines the response to therapy. Therefore, identification of the genetic lesions will be an essential feature of development of effective therapeutic regimens.

These chronic clonal hematopoietic disorders can evolve into acute myeloid leukemia (AML) as seen in $2-5 \%$ of PV or ET patients and 15-30\% of the PMF patients. However, the molecular mechanisms that lead to transformation are not well understood. A comparison of mutations in MPNs with those in post-MPN AML shows striking differences in the spectrum of gene sets involved [12]. The genetic lesions in post-MPN AML predominantly involved TP53, TET2, IDH1/2, ASXL1, SRSF2, RUNX1, DNMT3a, CBL along with increase in cytogenetic aberrations that included recurrent deletions $(4 \mathrm{q}, 5 \mathrm{q}$, 6p, 7p, 7q) and uniparental disomy (19q, 22q, 11q) [16]. One of the most interesting features of post-MPN AML was the loss of JAK2 ${ }^{\mathrm{V} 617 \mathrm{~F}}$ mutation in the transformed leukemic blasts [17]. It could be possible that JAK2 mutant clones and leukemic blast clones arise independently in the progenitor compartment or the JAK2 mutations are lost by deletion. An analysis of a cohort of $16 \mathrm{PV}$ patients with leukemic transformation showed that postPV MF and accelerated phase disease was associated with JAK2 mutated AML while AML with WT JAK2 arose from chronic phase disease possibly as a consequence of genotoxic therapy and damage to non JAK2 mutated HSCs [18]. Mutations in TP53 are rare in the chronic phase but their frequency goes upto $45 \%$ in the leukemic blast phase [19]. These implicate genomic instability and aberrant DNA damage response in the evolution of MPN from a chronic disease to acute leukemia. The precise sequence of mutations and their role in the evolutionary process remain an active area of investigation. Post-MPN AML shares spectra of mutated genes and several cytogenetic features with de novo AML. The increase in frequency of complex karyotype and loss of JAK2 mutations in post-MPN AML is associated with adverse prognosis. The loss of JAK2 mutation is also going to make them resistant to treatment with inhibitors specific for JAK2. Therefore, molecules that target other survival and proliferation regulatory pathways may have better therapeutic value. PI3K pathway has generated much interest in AML and is being investigated in several trials $[4,20]$. However, the clinical response has been highly variable and showed limited efficacy possibly due to poor patient selection [21]. A more personalized approach and careful patient selection on the basis of molecular lesions may yield better results. Since MPNs involve clonal expansion of more mature compartments that rely on 
cytokine responsiveness, the mutations in the components of cytokine signaling module and their effect on the therapeutic outcomes will be discussed in more detail in the next section.

\section{Pathogenic molecular lesions in cytokine signaling molecules leading to MPNs}

JAK2 is a non-receptor tyrosine kinase that associates with common $\beta$ chain of IL-3 receptor, gp130 family receptors and IFN- $\gamma$ receptor and transduces signals downstream of several cytokines [22]. The gain of function V617F mutation leading to constitutive activation of signaling has been detected in over $90 \%$ of patients with PV and in upto $50 \%$ patients with ET and PMF. The rare JAK2 ${ }^{\mathrm{V} 617 \mathrm{~F}}$ negative PV patients carry mutations in the exon 12 of JAK2 that leads to similar constitutive activation of the JAK2 and cytokine independent signaling. Thus, aberrant signaling through the JAK2 pathway accounts for almost all the cases of PV (Fig. 1). However, it is not clear why PV, ET and MF have a different phenotype despite carrying the same genetic mutation. It has been proposed that these differences may be attributable to mutation dose (copy number), differential downstream signaling and presence of additional genetic lesions [23]. In addition to mutations in JAK2, gain of function mutation in thrombopoietin receptor (TPO-R), myeloproliferative leukemia virus oncogene (MPL) at W515 have been reported in ET and PMF. Around 5 \% ET and $10 \%$ PMF patients negative for JAK2 ${ }^{\mathrm{V} 617 \mathrm{~F}}$, show presence of JAK2 exon 12 and MPL mutations (Fig. 1) that effectively lead to constitutive activation of the same signaling pathway $[24,25]$. Subsequently somatic mutations in calreticulin (CALR), a chaperone protein with known functions in regulating protein folding and cellular calcium metabolism, were detected in $67 \%$ of the ET and $88 \%$ of the
PMF patients that were negative for the JAK2 and MPL mutations (Fig. 1) [26]. These mutations were clustered in exon 9 and were absent in PV, AML, CML, MDS and CMML patients or in healthy individuals suggesting that these could serve as specific diagnostic markers for ET and PMF. The mutations involve deletions (53\%), insertions (32\%) and others leading to expression of the protein from an alternative reading frame. The resulting mutant calreticulin protein has a positively charged peptide at the $\mathrm{C}$ terminal instead of the negatively charged in the non-mutated protein. $\mathrm{Ba} / \mathrm{F} 3$ cells expressing the mutated protein acquire IL-3 independent proliferation capacity along with increased phosphorylation of STAT5 though the mechanistic details remain unknown [26]. In addition, loss of function mutations have been reported in negative regulators of cytokine signaling such as adaptor protein LNK (SH2B3) and CBL, a ubiquitin ligase that regulates the proteasomal degradation of some of the cytokine receptors. These mutations will also effectively lead to unregulated constitutive activation of the cytokine signaling pathways. It is interesting to note that mutations in JAK2, MPL and CALR are mostly mutually exclusive and converge on the activation of JAK/STAT signaling pathway. However, in terms of outcome, the median survival time for patients with ET (19.8 years) is longer than for PV (13.5 years) and PMF patients have the shortest median survival (5.9 years) [27]. Stratification of ET and PMF patients on the basis of presence of JAK2, MPL, CALR and triple negative mutations showed no significant survival differences in case of ET but mutational status affected the survival of PMF patients. The triple negative PMF patients had the shortest median survival time followed by JAK2 and MPL mutated, respectively. The longest survival times were observed in CALR mutated patients [27]. Surprisingly,
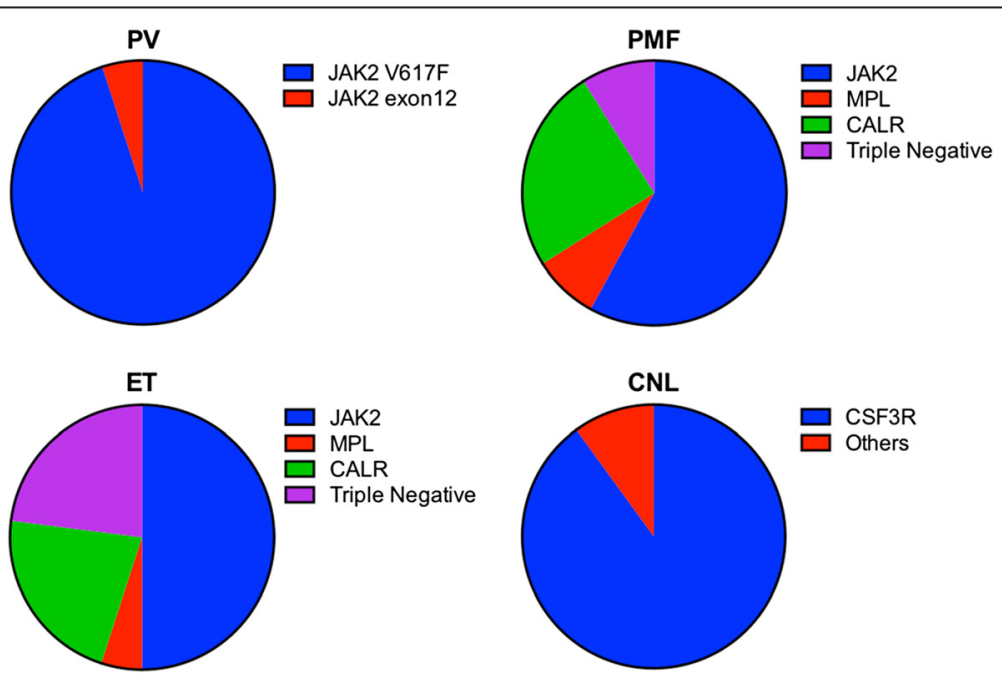

Fig. 1 Schematic representation of the distribution of mutations in molecules associated with cytokine signaling in Ph-ve MPNs. The approximate average values are shown 


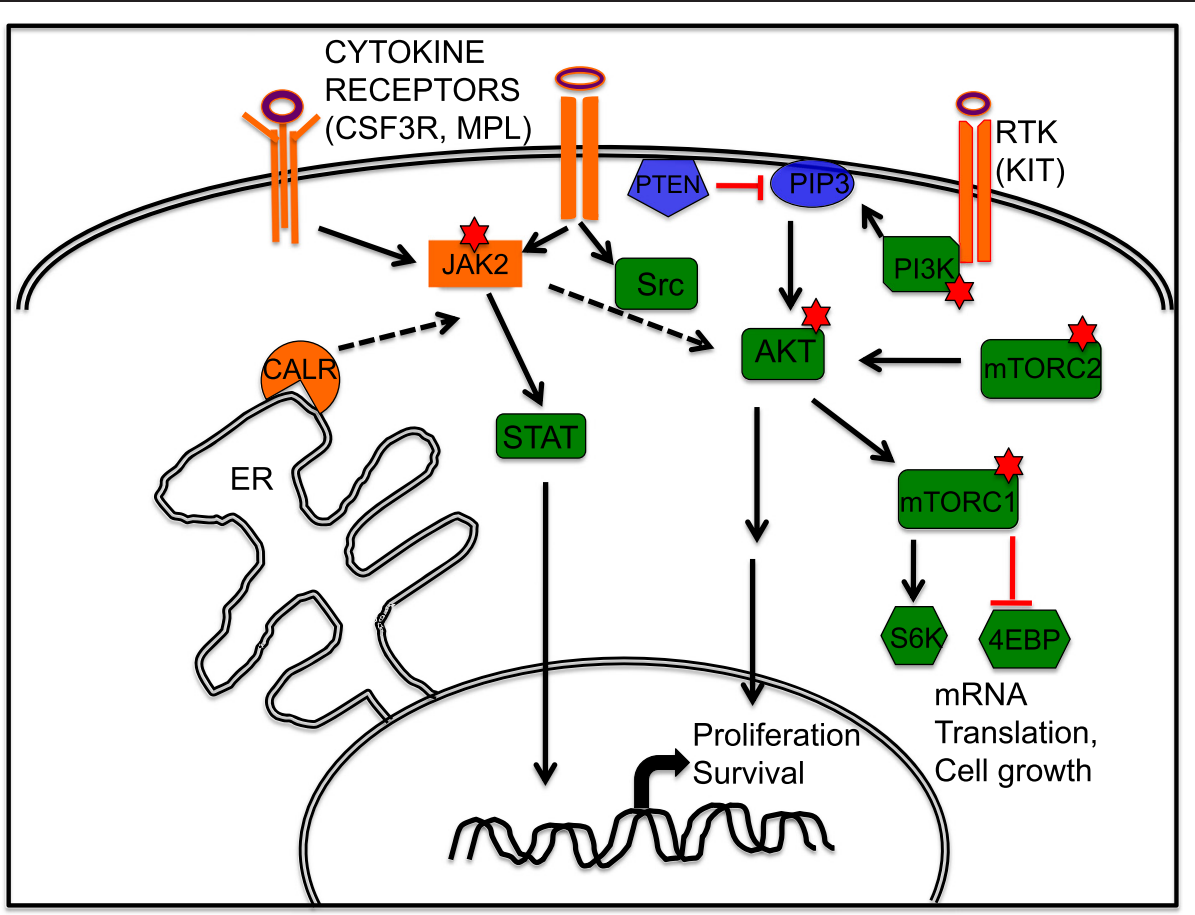

Fig. 2 Schematic showing the PI3K pathway and the targets for therapy. Red stars indicate the molecules that are being specifically targeted by small molecule inhibitors as single agents or in combination

this survival advantage in CALR mutated patients was restricted to those carrying the deletion mutations in CALR and in presence of insertion mutations the median survival times were similar to JAK2 mutated patients though both type of mutations result in change in charge and loss of ER retention motif at the C-terminus of the protein [28]. $\mathrm{Mu}-$ tations in chromatin regulators are frequent events in these MPNs and patients carrying ASXL1, IDH, EZH2 or SRFS2 are at higher risk. Presence of ASXL1 mutation along with CALR mutation was associated with reduction in median survival times but the worst prognosis was observed in patients having mutation in ASXL1 and non-mutated CALR [29]. These results further highlight the importance of defining the different genetic lesions and consequent signaling mechanisms for developing effective therapeutic regimen in MPNs.

Mastocytosis, the newly added subgroup to Ph-ve MPNs, involves clonal proliferation of mast cells and their accumulation in different organs. Mature mast cells express tyrosine kinase KIT, receptor for stem cell factor and activating mutations in KIT are present in mastocytosis and AML patients. Mutations at D816 are present in majority of the adult systemic mastocytosis (SM) patients and are also frequently associated with pediatric cutaneous mastocytosis [30-32]. Additional mutations in KIT, F522C, M541L, V560G, D820G and E839K, have also been reported in mastocytosis patients. Similar to JAK2 mutations, the gain of function mutations in KIT leads to constitutive activation of downstream signaling pathways and cytokine independent proliferation of the mutant cells. Tyrosine at position 719 within the cytoplasmic domain of mutant KIT plays an important role in the growth factor independent activation of STAT5 and PI3K/AKT/mTOR pathways [33]. Activation of the PI3K pathway contributes to cell survival through activation of Rho GTPase and Rho-associated coiled coilcontaining protein kinases (ROCK) and is essential for the transformation by KIT D816V [34]. Some of the KIT mutations are sensitive to inhibition by tyrosine kinase inhibitor, Imatinib but $\mathrm{D} 816 \mathrm{~V}$ mutation present in a majority of systemic mastocytosis patients is resistant to Imatinib [35, 36]. Dasatinib, a second-generation multi-kinase inhibitor, is able to inhibit KIT mutations that are resistant to Imanitib including D816V but it has met with little success in the clinic $[37,38]$. Thus, despite 2 decades of research to identify inhibitors of KIT, a cure for SM, an aggressive malignancy is still not available. This has forced the researchers to evaluate other downstream mediators of mutant KIT signaling such as SHP2 phosphatase and p21 activated kinase (PAK) as potential druggable targets [39-41].

A relatively rare, chronic neutrophilic leukemia $(\mathrm{CNL})$ characterized by elevated neutrophil counts is also included as a myeloproliferative neoplasm in the WHO 2008 classification. A search for molecular basis of CNL pathogenesis showed that deregulated signaling through mutations in cytokine receptor might be pivotal in 
development of CNL also. Truncation and membrane proximal mutations in colony-stimulating factor 3 receptor (CSF3R), a transmembrane receptor, that lead to cytokine independent proliferation appear to be specifically associated with CNL [27-29]. CSF3R regulates survival, proliferation and differentiation of granulocytes in response to granulocyte colony stimulating factor (G-CSF). T618I mutation in the membrane proximal region with or without additional mutations that truncate the cytoplasmic domain of CSF3R was observed in more than $80 \%$ patients diagnosed with CNL as per the WHO criteria [42-44]. Recapitulation of a fatal neutrophilic leukemia phenotype upon transplantation of CSF3R T618I mutation expressing hematopoietic cells further established a causal role for CSF3R mutation in development of CNL [45]. Mutations in CSF3R can therefore be a potential diagnostic marker for CNL. The membrane proximal point mutations vs truncation mutations in CSF3R may also have prognostic and clinical relevance. The membrane proximal mutations (T615A and T618I) in CSF3R were more potent in acquisition of cytokine independent growth and colony formation as compared to the truncation mutations due to activation of different signaling modules. The membrane proximal mutations activate the JAK2/STAT3 signaling axis and are sensitive to JAK inhibitor $[42,45]$ but insensitive to tyrosine kinase inhibitor Dasatinib. While the truncation mutations activate SRC family kinase, FGR/tyrosine kinase nonreceptor 2 signaling axis and are sensitive to dasatinib but resistant to JAK inhibitors [42]. In addition presence of mutations in SETBP1, encoding a nuclear protein that binds to DNA replication associated SET oncogene, determines the prognosis and response to therapy. Mutations clustered in the D868 to D874 region of SETBP1 were found in 30 $40 \%$ of the CNL patients and was associated with shorter life span. Interestingly, presence of SETBP1 mutation in addition to CSF3R T618I conferred resistance to not only conventional hydroxyurea therapy but also to JAK2 inhibitor, ruxolitinib [46]. Thus, JAK2 inhibition may be effective when only CSF3R T618I mutation is present but is likely to be ineffective in presence of CSF3R truncation or additional mutations such as SETBP1. Though it is not known which pathways are activated by SETBP1 that contribute to the resistance of double mutant cells. Since this data is based on a study with a single patient, further studies in with larger sample size will be required to establish the functional role of SETBP1 mutations.

Chronic eosinophilic leukemia, not otherwise specified (CEL-NOS) is another rare disease characterized by clonal expansion of eosinophils that has been included as a myeloproliferative neoplasm in the current classification system by WHO. CEL-NOS is highly aggressive with poor prognosis and high mortality. In a cohort of 10 CEL-NOS patients the median survival from the time of diagnosis was only 22.2 months [47]. $50 \%$ of the patients had acute transformation with median time of 20 months, and died with median survival of 2 months (range 1.0- 6.1) after acute transformation [47]. Since it is a rare disease, the small sample size makes it difficult to make conclusions about the molecular lesions that contribute to the development of this disease. In a recent study, Iurlo et al., [48] identified gain of function M541L mutation in KIT in 4 out of 5 CEL-NOS patients with non-mutated JAK2, BCR-ABL1, FIP1L1/PDGFR $\alpha$ and TEL/PDGFR $\beta$. These patients showed complete hematological remission upon treatment with low dose tyrosine kinase inhibitor (TKI) Imanitib, and were disease free upto 6 years after treatment with only one relapse occurring after 4 years [48]. These results are in stark contrast to poor prognosis and high mortality in CEL-NOS patients with conventional treatments [47]. Therefore, though presence of $\mathrm{KIT}^{\mathrm{M} 541 \mathrm{~L}}$ may not be a molecular marker for CEL-NOS as it has also been observed in pediatric mastocytosis [32] but identification of the mutational status can make a significant difference in the treatment decisions and outcome of this disease.

\section{Inhibition of JAK signaling in treatment of MPN}

Aberrant regulation of cytokine dependent signaling pathways appears to be the unifying molecular feature in all the Ph-ve MPNs. Acquisition of the mutations discussed above lead to enhanced cytokine sensitivity and clonal proliferation of lineage committed cells. In the absence of knowledge of the molecular mechanisms, the treatment options were limited to phlebotomy, hydroxyurea, interferons, and immunomodulatory agents to provide symptomatic relief to the patients [6]. JAK2 has been the target of choice since JAK2 ${ }^{\mathrm{V} 617 \mathrm{~F}}$ was the first and is the most frequent mutation associated with classical Ph- ve MPNs. Ruxolitinib (INC424/ INCB018424/ Jakafi), a specific inhibitor of JAK kinases, was the first inhibitor to be approved by FDA for the treatment of high and intermediate risk MF and PV. There was a marked and durable decrease in spleen size and disease associated pathologies upon treatment with Ruxolitinib as compared to the standard available therapy leading to improvements in the quality of life $[49,50]$. Success with Ruxolitinib raised the hopes but it was not curative. Additionally, treatment with Ruxolitinib was associated with thrombocytopenia and anemia in a significant number of MF patients undergoing the phase III trial. The beneficial effects of Ruxolitinib though encouraging, turned out to be limited in scope. [51, 52]. Partial success with Ruxolitinib has spurred the search for other JAK kinase inhibitors with improved efficacy and reduced toxicity. Pre clinical and clinical data with Fedratinib (TG101348/SAR302503), the second JAK kinase inhibitor to have entered phase III clinical trial, were promising but further development had to 
be discontinued following Wernicke's encephalopathy in these patients [53]. Similarly, clinical trials had to be terminated and further development discontinued due to severe pleiotropic neurological adverse effects in patients treated with JAK inhibitors, AZD1480 (clinical trial NCT01219543) or XL019 [54, 55]. None of the JAK2 inhibitors are specific to the mutated protein and in addition to JAK2 they can also inhibit JAK1 activity thereby leading to non-specific effects and toxicity. While new molecules continue to be evaluated for targeting the JAK/STAT pathway, a combinatorial approach is also being tested to reduce the toxicity and increase the efficacy $[56,57]$. Some of these combinations are designed to target the side effects of Ruxolitinib therapy such as anemia, MPN associated fibrosis, or the histone acetylation and DNA methylation which is frequently deregulated by the mutations in the regulators of the epigenome (Table 1). However, not all MPNs have mutations in JAK2 or activate the JAK/STAT signaling and are therefore, not likely to respond to JAK2 inhibition therapy. Some of the mutations, such as those in c-KIT can directly activate PI3K and other signaling pathways. In addition, very little is known about the mechanisms that contribute to enhanced proliferation and cytokine responsiveness in the triple negative group in PMF patients. PI3K/AKT/mTOR is a central signaling module and several other pathways converge on it to regulate cell survival and proliferation. It is also constitutively activated in MPNs and targeting it either alone or in combination has yielded encouraging results. Since the $\mathrm{PI} 3 \mathrm{~K} / \mathrm{AKT} / \mathrm{mTOR}$ signaling axis is deregulated in various other cancers, significant efforts have been channeled to identify small molecular inhibitors of this pathway. These molecules are already in various stages of pre clinical and clinical evaluations. Therefore, these inhibitors of PI3K pathway can become rapidly available to MPN patients.

\section{Phosphatidylinositol 3 Kinase pathway in MPN}

There are three classes of PI3K and the focus will be on class IA since it plays a central role in normal development as well as in the pathogenesis of different cancers. Phosphatidylinositol 3 kinase pathway is activated at the cell surface and integrates signals from cytokines, growth factors and environmental cues and transmits them through AKT and mTOR to effector molecules that control protein synthesis, growth, survival and proliferation $[58,59]$. The active PI3K enzyme consists of a heterodimer of a catalytic subunit and a regulatory subunit. The catalytic subunits $\mathrm{p} 110 \alpha, \mathrm{p} 110 \beta$, and $\mathrm{p} 110 \delta$ are encoded by Pik3ca, Pik3cb, and Pik3cd, respectively while Pik3r1, Pik3r2, and Pik3r3 encode the class IA PI3K regulatory subunits $\mathrm{p} 85 \alpha, \mathrm{p} 85 \beta$ and $\mathrm{p} 55 \gamma$, respectively. Alternate codon usage from Pi3r1 generates two additional

Table 1 Ongoing clinical evaluations of ruxolitinib in combination with other compounds for treatment of MPNs

\begin{tabular}{|c|c|c|c|c|c|}
\hline Compounds & Target/mechanism & $\begin{array}{l}\text { National Clinical Trial } \\
\text { Identifier }\end{array}$ & Phase & Condition & Status \\
\hline Decitabine & $\begin{array}{l}\text { Anti-metabolite chemotherapeutic, } \\
\text { DNA demethylation }\end{array}$ & NCT02076191 & $|/| \mid$ & $\begin{array}{l}\text { Accelerated or } \\
\text { blast phase MPN }\end{array}$ & Recruiting \\
\hline \multirow[t]{2}{*}{ Azacitidine (Vidaza) } & \multirow{2}{*}{$\begin{array}{l}\text { Chemical analogue of nucleoside } \\
\text { cytidine, antimetabloite chemotherapeutic }\end{array}$} & NCT01787487 & III & MF, MDS/MPN & Recruiting \\
\hline & & NCT02257138 & $|/| \mid$ & $\begin{array}{l}\text { AML, post } \\
\text { MPN-AML }\end{array}$ & Active, not recruiting \\
\hline Danazol & $\begin{array}{l}\text { Synthetic steroid derived from ethisterone, } \\
\text { used in endometriosis treatment }\end{array}$ & NCT01732445 & $\|$ & $\begin{array}{l}\text { Anemia in PMF, } \\
\text { post ET/ PV MF }\end{array}$ & $\begin{array}{l}\text { Recruitment suspended } \\
\text { for interim data to mature }\end{array}$ \\
\hline Pracinostat (SB939) & $\begin{array}{l}\text { Hydroxamic acid based histone deacetylatase } \\
\text { inhibitor of class } 1 / 2 / 4 \text { HDACs }\end{array}$ & NCT02267278 & $\|$ & MF & Active, not recruiting \\
\hline \multirow[t]{2}{*}{ Panobinostat (LBH589) } & \multirow{2}{*}{$\begin{array}{l}\text { Hydroxamic acid based non selective HDAC } \\
\text { inhibitor }\end{array}$} & NCT01693601 & $|/| \mid$ & MF & Recruiting \\
\hline & & NCT01433445 & । & $\begin{array}{l}\text { PMF, post } \\
\text { ET/ PV MF }\end{array}$ & Active, not recruiting \\
\hline $\begin{array}{l}\text { Pomalidomide } \\
\text { (CC-4047-MM-002) }\end{array}$ & $\begin{array}{l}\text { Derivative of thalidomide, inhibits angiogenesis, } \\
\text { immunomodulator }\end{array}$ & NCT01644110 & $|/| \mid$ & $\begin{array}{l}\text { PMF, post } \\
\text { ET/PV MF }\end{array}$ & Recruiting \\
\hline Lenalidomide & Anti-angiogenic, immunomodulator & NCT01375140 & $\|$ & MF & Active, not recruiting \\
\hline $\begin{array}{l}\text { Simtuzumab } \\
\text { (GS-6624) }\end{array}$ & $\begin{array}{l}\text { Humanized monoclonal antibody, binds to } \\
\text { LOXL2 and inhibits fibrosis }\end{array}$ & NCT01369498 & $\|$ & $\begin{array}{l}\text { PMF, post } \\
\text { ET/PV MF }\end{array}$ & Completed \\
\hline PRM-151 & $\begin{array}{l}\text { Recombinant pentraxin-2 protein (acute } \\
\text { immunological responses) inhibits fibrosis }\end{array}$ & NCT01981850 & $\|$ & $\begin{array}{l}\text { PMF, post } \\
\text { ET/PV MF }\end{array}$ & Recruiting \\
\hline BKM120 & PI3K inhibitor & NCT01730248 & । & $\begin{array}{l}\text { PMF, post } \\
\text { ET/PV MF }\end{array}$ & Recruiting \\
\hline LDE225 & $\begin{array}{l}\text { Investigational inhibitor of Smoothened (SMO), } \\
\text { a regulator of hedgehog signaling pathway }\end{array}$ & NCT01787552 & $\mid \mathrm{b} / \mathrm{ll}$ & PMF, ET, MPD & Recruiting \\
\hline
\end{tabular}


regulatory units, $\mathrm{p} 55 \alpha$ and $\mathrm{p} 50 \alpha$. There is no specificity with regard to association between regulatory and catalytic subunits. Any regulatory subunit can associate with any of the catalytic subunits present. Cell type specificity in PI3K activity is achieved through cell lineage specific expression of the different isoforms. Class 1 PI3K utilize the lipid substrate, phosphatidylionsitol-45, biphsophate (PIP2) and catalyze the phosphorylation at 3-position in the ring to generate the active second messenger, phosphatidylinositol3,4,5- triphoshpate (PIP3). In unstimulated cells, the regulatory subunit binds to the catalytic subunit and inhibits the catalytic activity. Upon stimulation, the regulatory subunit is recruited to the phosphotyrosine proteins present at the cell membrane and the catalytic unit catalyzes the formation of PIP3 that in turn acts as a tethering moiety for AKT. Upon recruitment to the membrane, AKT is phosphorylated and in turn activates mammalian target of rapamycin (mTOR), a serine threonine kinase and other proteins involved in cell survival and proliferation (Fig. 2). The signaling is attenuated by the lipid phosphatases, PTEN and SHIP that dephosphorylate and convert PIP3 back to PIP2 and the inhibitory feedback circuitry $[60,61]$.

Hyperactivation of the PI3K signaling module has been observed in a large number of solid cancers and hematological malignancies. This may either be due to oncogenic activation of receptor tyrosine kinases and/or also due to increased expression, copy number gain, amplifications or mutations in Pik3ca, Pik3r1, AKT, TSC1/2 and PTEN $[62,63]$. In MPN patient bone marrow biopsy samples with JAK2 ${ }^{\mathrm{V} 617 \mathrm{~F}}$ or $\mathrm{KIT}^{\mathrm{D} 816 \mathrm{~V}}$ mutation, increase in phosphorylation of AKT indicates constitutive activation of the PI3K pathway [64]. PI3K regulatory subunits $\mathrm{p} 85 \alpha$ and $\mathrm{p} 85 \beta$ appear to have different roles in transformation of myeloid cells by mutant KIT. While genetic deletion of $\mathrm{p} 85 \alpha$ abrogated the cytokine independent growth and leukemogenic activity of $\mathrm{KIT}^{\mathrm{D} 814 \mathrm{~V}}$, deletion of $\mathrm{p} 85 \beta$ had no effect on the growth factor independent proliferation $[65,66]$. Similarly, consistent with the selective expression of the p110 catalytic subunit in the leucocytes, specific inactivation of $\mathrm{p} 110 \delta$ but not that of $\mathrm{p} 110 \alpha$ inhibited the hypersensitivity to GM-CSF due to presence of activating mutation in Shp2 phosphatase and subsequent activation of the PI3K signaling module [67]. In addition to contributing to pathogenesis of neoplasms, constitutive activation of PI3K pathway also contributes to resistance to tyrosine kinase inhibitors (TKI). This development of resistance is not due induced mutations in BCR-ABL1 [68]. The epigenetic silencing of PTEN in response to therapy and consequent activation of the PI3K/AKT along with other pro-survival pathways possibly mediates drug resistance [69]. Given the crucial role of PI3K signaling module there is intense interest in finding specific drugs and more than 40 molecules by different pharmaceutical companies are in different stages of clinical evaluations (Table 2).

\section{Targeting the PI3K Pathway}

The PI3K signaling module has emerged as one of the most attractive target in cancer therapeutics due to its central role in integrating signals from different receptor kinases to regulate cell survival and proliferation. Significant efforts have been devoted to identify small molecule inhibitors that can block the PI3K pathway at one or more of the signaling nodes (Table 2). Accordingly, they can be broadly classified as inhibitors of (1) PI3K (2) AKT and (3) mTOR (Fig. 2). Additionally some inhibitors can target the PI3K pathway at more than one node and they are grouped as dualspecificity inhibitors. These molecules are in various stages of pre-clinical and clinical evaluation either as single agents or in combination with other therapeutics in advanced solid tumors and hematological malignancies. Though some of these molecules hold promise, so far the success has been limited. Clinical trials with GSK1059615, a PI3K a inhibitor (NCT00695448), GSK690693, inhibitor of AKT (NCT00493818) and AZD2014, mTORC1/2 inhibitor (NCT00493818) had to be terminated due to limited efficacy or drug related toxicities [70]. While further development of GSK1059615 and GSK690693 has been stopped, AZD2014 is being evaluated in several clinical trials in combination with other agents (Table 2). Some of the PI3K pathway inhibitors have also been evaluated in models of MPN and have entered the clinic as discussed below. As the safety and efficacy of these small molecules is established in the early clinical trials with solid cancers and lymphomas, clinicians will have more options to choose from while designing the therapeutic strategies for MPN patients based on the mutational status and molecular markers. Interestingly, majority of the small molecule inhibitors of the PI3K signaling module have oral bioavailability (Table 2) which is better suited for the management of chronic diseases like MPN and ensuring patient compliance.

\section{Inhibitors of PI3K}

The inhibitors of the class IA PI3K can be further subdivided into pan PI3K inhibitors and isoform specific inhibitors. The first generation pan Class I PI3K inhibitors, Wortmanin and LY294002 had potent activity in vitro model systems but they did not make it to the clinic due to severe toxicities observed in vivo. PX-866, a synthetic derivative of wortmannin and irreversible pan PI3K inhibitor, was found to be safe and well tolerated in patients who had already undergone 3 or more therapies for advanced solid cancers [71]. Interestingly, PX-866 also inhibited TGF- $\alpha /$ EGFR induced lung fibrosis in preclinical models when used as a single agent or in combination with MEK inhibitor $[72,73]$. These results raise the hope that inhibition of 
Table 2 Inhibitors of the PI3K/AKT/mTOR pathway in the clinic

\begin{tabular}{|c|c|c|c|c|c|}
\hline Compound & Target specificity & Availability & Mechanism & Phase & Cancer \\
\hline Afuresertib (GSK2110183) & AKT 1/2/3 & Oral & ATP competitive & I, II & MM, CLL, Solid cancers \\
\hline BAY1125976 & AKT 1/2 & Oral & $\begin{array}{l}\text { Allosteric, Non-ATP } \\
\text { competitive }\end{array}$ & I & Advanced solid tumors \\
\hline RX-0201 (Archexin) & AKT 1 & IV & $\begin{array}{l}\text { Antisense } \\
\text { oligodeoxymucleotide }\end{array}$ & $|/| \mid, \|$ & Pancreatic, Renal \\
\hline ARQ 092 & Pan AKT, selectivity for AKT1 & Oral & ATP competitive & । & $\begin{array}{l}\text { Solid tumors, recurrent } \\
\text { Lymphoma }\end{array}$ \\
\hline GDC-0068 & AKT 1/2/3 & Oral & Non-ATP competitive & I, II & Solid cancers \\
\hline Uprosertib (GSK2141795) & AKT 1/2/3 & Oral & ATP competitive & $\|$ & Solid cancers, AML, MM \\
\hline MK2206 & Pan AKT, selectivity for AKT1 & Oral & $\begin{array}{l}\text { Allosteric, Non-ATP } \\
\text { competitive }\end{array}$ & $\|$ & Solid tumors, lymphoma \\
\hline SR13668 & AKT & Oral & Blocks AKT phosphorylation & । & $\begin{array}{l}\text { Healthy volunteers } \\
\text { (completed) }\end{array}$ \\
\hline LY2780301 & AKT/p70S6K & Oral & ATP competitive & $|/| \mid$ & $\begin{array}{l}\text { Advanced solid tumors, } \\
\text { non-hogdkin's lymphoma }\end{array}$ \\
\hline AZD5363 & AKT, 1/2/3 P70S6K/PKA & Oral & ATP competitive & $|/| \mid$ & Solid cancers \\
\hline ONC201 (TIC10) & AKT/ERK & Oral & Indirect & $|/| \mid$ & Advanced solid tumors \\
\hline BKM120 (buparlisib) & PI3K & Oral & ATP competitive & II, III & Advanced cancers \\
\hline ZSTK474 & PI3K & Oral & $\begin{array}{l}\text { S-triazine derivative, } \\
\text { ATP-competitive }\end{array}$ & $|/| \mid$ & Advanced solid tumors \\
\hline Copanlisib (BAY 80-6946) & PI3K & IV & $\begin{array}{l}\text { Imidazolinoquinazoline } \\
\text { derivative }\end{array}$ & ।. II & Advanced solid tumors, NHL \\
\hline PX-866 & PI3K & Oral & $\begin{array}{l}\text { Wortmannin analogue, } \\
\text { irreversibly binds catalytic } \\
\text { site }\end{array}$ & $|/| \mid$ & Solid tumors \\
\hline XL147 (SAR245408) & PI3K (MEK/ERK) & Oral & ATP competitive & I & Advanced solid tumors \\
\hline BYL719 & PI3K alpha & Oral & 2-aminothiazole derivative & $|/| \mid$ & Advanced solid tumors \\
\hline INK1117 (MLN1117) & PI3K alpha & Oral & & । & Metastatic solid tumors \\
\hline AZD8186 & PI3K beta & Oral & & । & $\begin{array}{l}\text { CRPC, sqNSCLC, TNBC, PTEN } \\
\text { deficient advanced cancers }\end{array}$ \\
\hline GSK2636771 & PI3K beta & Oral & substituted benzimidazole & $|/| \mid$ & $\begin{array}{l}\text { CRPC, PTEN deficient solid } \\
\text { tumors }\end{array}$ \\
\hline $\begin{array}{l}\text { Idelalisib (Zydelig, CAL-101, } \\
\text { GS-1101) }\end{array}$ & PI3K delta & Oral & Quinazoline class & III & $\begin{array}{l}\mathrm{NHL}, \mathrm{FDA} \text { approved for } \\
\text { relapsed CLL, SLL, FL }\end{array}$ \\
\hline INCB040093 & PI3K delta & Oral & & । & B cell malignancies \\
\hline INCB050465 & PI3K delta & & & । & $\begin{array}{l}\text { Relaposed/ refractory B cell } \\
\text { malignancies }\end{array}$ \\
\hline BAY1082439 & PI3K alpha/beta & Oral & & । & Advanced solid tumors \\
\hline GDC-0941 bismesylate & PI3K alpha/delta & Oral & ATP competitive & $|/| \mid$ & TNBC, NSCLC \\
\hline AZD8835 & PI3K alpha/delta & Oral & & I & Advanced solid tumors \\
\hline GS-9820 (CAL-120) & PI3K beta/delta & Oral & & $\mathrm{lb}$ & Lymphoid malignancies \\
\hline RP6530 & PI3K gamma/delta & Oral & & । & Hematological malignancies \\
\hline $\mid \mathrm{PI}-145$ & PI3K gamma/delta & Oral & ATP competitive & I, III & $\begin{array}{l}\text { Hematological malignancies, } \\
\text { follicular lymphoma }\end{array}$ \\
\hline DCBCI0901 & $\mathrm{PI3K} / \mathrm{mTORC} 1 / 2$ & IV & & । & Advanced solid tumors \\
\hline P7170 & PI3K/mTOR/DNA-PK/ALK-1 & Oral & & I & Advanced refractory tumors \\
\hline VS-5584 & $\mathrm{PI} 3 \mathrm{~K} / \mathrm{mTOR}$ & Oral & & । & $\begin{array}{l}\text { Non hematological cancers, } \\
\text { metastatic cancers, Lymphoma }\end{array}$ \\
\hline DS-7423 & $\mathrm{PI} 3 \mathrm{~K} / \mathrm{mTOR}$ & Oral & & I & Solid tumors, completed \\
\hline PF-05212384 & $\mathrm{PI} 3 \mathrm{~K} / \mathrm{mTOR}$ & IV & & । & Advanced solid tumors \\
\hline
\end{tabular}


Table 2 Inhibitors of the PI3K/AKT/mTOR pathway in the clinic (Continued)

\begin{tabular}{|c|c|c|c|c|c|}
\hline BEZ235 & $\mathrm{PI} 3 \mathrm{~K} / \mathrm{mTOR}$ & Oral & $\begin{array}{l}\text { Imidazo }(4,5) \text { quinoline } \\
\text { derivative, } \\
\text { ATP competitive }\end{array}$ & $|/ I|$ & Advanced solid tumors \\
\hline XL765 (SAR245409) & $\mathrm{PI3K} / \mathrm{mTOR}$ & Oral & & $|/| \mid$ & Advanced solid tumors \\
\hline BGT226 & $\mathrm{PI} 3 \mathrm{~K} / \mathrm{mTOR}$ & Oral & & $|/| \mid$ & $\begin{array}{l}\text { Advanced solid cancers, } \\
\text { completed }\end{array}$ \\
\hline GDC-0980 & $\mathrm{PI3K} / \mathrm{mTOR}$ & & & $|/| \mid$ & NHL, EC, Solid tumors \\
\hline GSK2126458 & $\mathrm{PI} 3 \mathrm{~K} / \mathrm{mTOR}$ & Oral & $\begin{array}{l}\text { Pyridylsulfonamide } \\
\text { derivative }\end{array}$ & I & Refractory solid tumors \\
\hline $\begin{array}{l}\text { PWT33597 mesylate } \\
\text { (VCD-597) }\end{array}$ & PI3K alpha/mTOR & Oral & $\begin{array}{l}\text { Derived from pan-Class I } \\
\text { PI3-kinase ATP competitive } \\
\text { inhibitor ZSTK474 }\end{array}$ & । & Advanced malignancies \\
\hline MLN0128 (INK128) & TORC $1 / 2$ & Oral & ATP competitive & l,II & $\begin{array}{l}\text { Advanced solid and } \\
\text { hematological malignancies }\end{array}$ \\
\hline OSI-027 & TORC $1 / 2$ & Oral & $\begin{array}{l}\text { 4,5,7-trisubstituted imidazo } \\
{[5,1-f] \text { triazine }}\end{array}$ & 1 & Solid tumor, lymphoma \\
\hline AZD8055 & TORC $1 / 2$ & Oral & $\begin{array}{l}\text { ATP competitive, inhibits } \\
\text { kinase activity }\end{array}$ & 1 & Advanced cancers \\
\hline AZD2014 & TORC $1 / 2$ & Oral & ATP competitive & $|/| \mid$ & Advanced solid cancers \\
\hline CC-223 & TORC $1 / 2$ & Oral & ATP competitive & $|/| \mid$ & $\begin{array}{l}\text { MM, DLBCL, NHL, solid } \\
\text { cancers }\end{array}$ \\
\hline ME-344 (NV-128 & mTOR & IV & Isoflavone derivative & 1 & Solid tumors \\
\hline ABTL0812 & TORC1/2, DHFR & Oral & Lipid analogue & 1 & Advanced tumors \\
\hline CUDC-907 & PI3K/HDAC & Oral & & I & Advanced solid tumors, MM \\
\hline
\end{tabular}

the PI3K pathway by PX-866 may be effective in managing PMF and post ET/PV-MF. BKM120 is another promising pan class I PI3K inhibitor that has reached phase III in clinical trials with advanced solid tumors (Table 2). In addition to inhibiting the tumor cell growth, BKM120 also blocked the protective signals from the microenvironment in preclinical models of T-ALL and CLL $[74,75]$. BKM120 is currently being investigated in the clinic in combination with ruxolitinib for treatment of MF (Table 1). However, it remains to be seen if any of these PI3K inhibitors will be successfully applied for the management of MPNs.

While promising leads have been obtained with pan class I PI3K inhibitors, efforts have also been directed to develop isoform specific inhibitors to limit systemic toxicities (Table 2). While p $110 \alpha$ and $\beta$ isoforms have a more ubiquitous tissue distribution, p110 $\delta$ has a more restricted expression in the hematopoietic system. Therefore, inhibitors directed at $\mathrm{p} 110 \delta$ catalytic subunit are being preferentially evaluated in hematological malignancies (Table 2). Idelalisib (also known as Zydelig, CAL-101, GS-1101) became the first in this class of inhibitors to get FDA approval for use in relapsed and refractory CLL, follicular B-cell nonHodgkin lymphoma and relapsed small lymphocytic lymphoma. In the clinic, Idelalisib is efficacious as a single agent as well as in combination with rituximab in CLL patients who had treatment refractory disease or were unsuitable for standard chemotherapy [76, 77]. In pre-clinical evaluations, a PI3K $\alpha / \delta$ inhibitor, GDC-0941 inhibited the proliferation driven by mutant KIT in 32D cells [33] while Idelalisib and another PI3K $\delta$ specific inhibitor, GS-9820 (Table 2) inhibited the GM-CSF induced proliferation of bone marrow cells expressing the constitutively active Shp2 phosphatase mutant with concomitant reduction in AKT phosphorylation [67]. These results indicate that isoform specific inhibition of p110 catalytic subunit may also benefit MPN patients. Idelalisib is particularly interesting as in addition to induction of apoptosis in the leukemic cells, it antagonizes the protective effect of bone marrow stroma on CLL cells by blocking the expression of BCR induced lymphocyte cytosolic protein 1 (LCP1). It also interferes with cytoskeleton rearrangement and migration thereby leading to CLL cell de-adhesion and apoptosis [78, 79]. IPI-145, inhibitor of p110 $\delta$ and $\gamma$ isoforms has also been found to be safe and efficacious in phase I trial. Notably, IPI-145 also antagonized extracellular survival signals and sensitized ibrutinib resistant cells with BTK ${ }^{\mathrm{C} 481 \mathrm{~S}}$ mutation [80]. IPI-145 also exerts anti-inflammatory activity through modulation of chemokine secretion, neutrophil 
migration and activation of basophils [81]. It is interesting to note that some of these isoform specific inhibitors are not only toxic to the transformed cells but can also counter the protective effects of the microenvironment and reduce inflammation, two of the critical contributors to leukemic transformation and resistance to therapeutics in vivo. Taken together these results provide a strong rationale for evaluation of PI3K inhibitors in MPN models but the success is likely to be dependent upon patient selection on the basis of genetic lesions.

\section{Inhibitors of $m$ TOR}

Mammalian target of rapamycin (mTOR), a serine threonine kinase with homology to the PI3K, is present as part of two different complexes - mTORC1 and mTORC2 (Fig. 2). mTORC1 includes raptor, mLST8, PRAS40 and DEPTOR and is mainly involved in regulating cell growth and protein synthesis through its downstream effectors, S6 kinase and 4E-Binding Protein 1 (4EBP1). On the other hand, mTORC2 complex includes rictor, mLST8, DEPTOR, mSin 1 and protor. mTORC2 plays a role in survival signaling through phosphorylation of $\mathrm{AKT}^{\mathrm{S} 473}$ and serum and glucocorticoid-inducible kinase (SGK). Rapamycin was the first allosteric inhibitor of the mTOR complex and has led to development of next generation inhibitors referred to as rapalogs that include everolimus and temsirolimus [82]. These primarily inhibit mTORC1 by interacting with FK binding protein 12 (FKB12) and have little or no effect on mTORC2. Differential expression of mTORC1 and mTORC2 in immature and neoplastic mast cells versus the terminally differentiated mast cells may provide a therapeutic window for selectively targeting the mTORC2 [83]. It may be possible to inhibit the proliferation of only the neoplastic cells while leaving the functionality of terminally differentiated mast cells intact. Rapamycin was reported to selectively inhibit phosphorylation of 4E-BP1 and induce apoptosis in mast cells with D814V mutation [84]. These results suggested that targeting mTOR might be successful in treatment of systemic mastocytosis. However, no clinical benefit was observed in a phase II clinical trail with everolimus (RAD001) in a cohort of 10 patients with either indolent or aggressive systematic mastocytosis [85]. However it is worth noting that 6 of these 10 patients had been treated with other agents previously and had possibly activated compensatory mechanisms that might have made them resistant to therapy. More promising results were observed in another phase I/ II clinical trial with everolimus in a cohort of 39 patients with primary and post-PV/post-ET MF even though in this study too over $80 \%$ of the patients had been unresponsive to previous treatment with at least one conventional therapeutic regimen of either cytotoxic drugs, interferon therapy, erythropoiesis stimulation, or immunomodulatory agents [86].
$44 \%$ response rate was observed for splenomegaly while complete resolution of constitutional symptoms and pruritus was reported in $69 \%$ and $80 \%$ of the patients, respectively with modest hematological and non-hematological toxicities. Patient response showed strong correlation with reduction in p70S6K phosphorylation in responders while no significant differences were observed in the plasma proteins or inflammatory cytokines and circulating $\mathrm{CD}^{+} 4^{+}$cells [86]. Interestingly, the response to Everolimus was independent of the mutation status of JAK2 or MPL [86]. These results demonstrate that inhibition of mTOR by rapalogs can provide symptomatic relief leading to improvement in quality of life.

In addition to the rapalogs, ATP competitive inhibitors of mTOR complex have been developed. Since these inhibitors inihbit both mTORC complexes, they target the upstream mTORC2 complex that activates AKT as well as its downstream substrate mTORC1 complex thereby effectively acting on the pathway at 3 nodes (Fig. 2). The growth factor independent proliferation of 32D cells with mutant KIT was susceptible to inhibition by the mTORC1/2 inhibitor, AZD8055 [33]. Similarly, in another recent pre-clinical study, PP242, a ATP competitive inhibitor of mTOR was shown to inhibit cell cycle progression and colony formation as effectively as RAD001 (everolimus) in erythropoietin-independent cell lines and progenitor cells from PMF and PV patients with JAK2 ${ }^{\mathrm{V} 617 \mathrm{~F}}$ mutation. It is worth noting that PP242 was also effective against RAD001 resistant JAK2 ${ }^{\mathrm{V} 617 \mathrm{~F}}$ human cell lines and had pro-apoptotic activity in contrast to the cytostatic activity of RAD001 [87]. These differences can be attributed to the ability of PP242 to inhibit both TORC1/2 while RAD001 inhibits only TORC1. 4E-BP1 has rapamycin resistant phosphorylation at $\mathrm{Thr}^{37 / 46}$ that is possibly mediated through serine/threonine kinase Pim2 and maintains cap dependent translation [88]. Therefore, catalytic site inhibitors of mTOR are more likely to be successful as therapeutic drugs. However, while the inhibitors effectively block mTOR activity, they also block the feedback inhibition leading to increase in AKT $\mathrm{Thr}^{308}$ phosphorylation by PI3K/PDK1 hyper activation [89]. Taken together the data from pre-clinical and clinical trials supports a pivotal role for mTOR in pathogenesis of MPNs. Further, taking into consideration the moderate success observed in patients that had already developed resistance, inclusion of mTOR inhibitors in the first line therapy may prove to be more beneficial.

\section{Inhibitors of $A K T / P K B$}

$\mathrm{AKT}$, a serine threonine kinase with three isoforms encoded by different genes, is another potential target in the PI3K signaling pathway. AKT is recruited to the cell 
membrane in response to the lipid second messenger, PIP3 through its pleckstrin homology domain where it is phosphorylated by phosphoinositide-dependent protein kinase 1 (PDK1) and $\mathrm{mTORC} 2$ at $\mathrm{Th}^{308}$ and $\mathrm{S}^{473}$ which in turn regulates TSC2/ mTORC1, GSK3 $\beta$, MDM2 and $\mathrm{Bcl} 2$ family proteins. Inhibitors of the AKT kinases in the clinic include ATP-competitive molecules, allosteric inhibitors, lipid mimetics and antisense nucleotide (Table 2). Some of these inhibitors in the pre clinical studies using in vitro and mouse models of MPN have shown promise. An allosteric, non-ATP competitive and orally bioavailable AKT inhibitor, MK-2206, has been established as safe and tolerable in Phase I clinical trials in patients with solid tumors. MK-2206 inhibited AKT phosphorylation in MPN cell lines with JAK2 ${ }^{\mathrm{V} 617 \mathrm{~F}}$ mutation as well as in $\mathrm{CD} 34^{+}$peripheral blood cells. This was associated with reduction in phosphorylation of proapoptotic protein, BAD and induction of cell death [90]. MK-2206 was also efficacious in a mouse model of myelofibrosis induced by transplanting MPL ${ }^{\mathrm{W} 515 \mathrm{~L}}$ expressing cells. Treatment with MK-2206 was associated with reduction in $\mathrm{CD}_{4} 1^{+}$cells and AKT phosphorylation and in the bone marrow, significant reduction in peripheral WBC and megakaryocytes in liver, spleen and bone marrow with no overt hematological toxicity [90]. Interestingly activation of AKT in AML patients contributes to acquisition of resistance to Gemtuzumab ozogamicin(GO), an anti-CD33 antibody conjugated to a calicheamicin- $\gamma(1)$ derivative and MK-2206 can sensitize these cells in vitro [91]. These results provide further evidence of activation of the PI3K pathway in MPNs with mutations in cytokine/JAK2 pathway and are encouraging for specific targeting of AKT during the chronic and leukemic phases. However, the benefits in the clinic are yet to be realized.

Two other inhibitors of AKT activation, UCN-01, a staurosproine derivative that blocks PDK1 mediated phosphorylation of AKT [92] and Perifosine an orally available alkylphospholipid that prevents recruitment of AKT to membrane for activation [93], were evaluated in combination in a phase I trial in AML and MDS patients. Though the combination was well tolerated and phosphorylation of ribosomal protein S6 was reduced in the blast samples, the combination was not effective in inhibiting AKT phosphorylation [94]. However it is worth nothing that a demonstrable increase in baseline phosphorylation of the AKT target was not present in all the patients. Furthermore, validity of using $\mathrm{S} 6$ phosphorylation as biomarker for $\mathrm{AKT} / \mathrm{mTORC} 1$ inhibition is questionable as phosphorylation of $4 \mathrm{E}-\mathrm{BP} 1$, another mTORC1 target does not correlate with S6 phosphorylation [88]. These results highlight the need for sensitive and predictive biomarkers for assessing the effectiveness of the inhibitors. It is also possible that all patients may not have constitutive activation of AKT and therefore, may not be good candidates for therapeutic regimens based on inhibition of AKT. A more personalized approach based on molecular characteristics of individual patients is more likely to be successful. Additionally, as discussed below, it might be more prudent to combine inhibitors that target different pathways rather than targeting the same molecule.

\section{Inhibitors with dual specificity}

Development of dual specificity inhibitors is an alternative approach to blocking the activation of PI3K/AKT/ mTOR pathway at multiple levels rather than a single node at a time. These take advantage of the high degree of homology in the kinase domains of PI3K and mTOR. The dual specificity inhibitors bind to the active site of both, PI3K and mTOR. BEZ235, a dual specificity inhibitor of the PI3K/ mTOR pathway developed by Novartis inhibited the proliferation of growth factor independent, clonal proerythroblastic murine cells as well as human mast cell line carrying the D816V mutation with cells being arrested in $\mathrm{G} 1$ phase $[95,96]$. It was interesting to note that despite increasing the drug concentration, complete inhibition could not be achieved. Interestingly, there was no increase in cell death at growth inhibitory concentrations. Cell proliferation and survival may be regulated by parallel pathways and it would be possible to get synergism by a combination that targets these two pathways. Consistent with this notion, strong synergy and complete inhibition of proliferation with induction of cell death was observed when BEZ235 was combined with UO126 that abrogated MEK/ERK signaling or Obatoclax that blocked pro-survival signaling by the $\mathrm{Bcl} 2$ family proteins [96]. In contrast, in cells expressing $\mathrm{JAK}^{\mathrm{V} 617 \mathrm{~F}}, \mathrm{BCR}-\mathrm{ABL} 1$ or $\mathrm{BRAF}^{\mathrm{V} 600 \mathrm{~K}}$, treatment with BEZ235 was able to overcome the resistance to inhibitors conferred by mutation in $G$ protein $\beta 1$ subunit and induced apoptosis $[97,98]$. In addition to being effective against cell lines carrying the JAK2 mutation and primary MF cells, BEZ235 also demonstrated synergism with JAK2 inhibitors, TG101209 and SAR302503 [97]. XL147, a pan PI3K inhibitor is in phase I trial in patients with advanced solid cancers. It was interesting to note that as expected, XL147 inhibited phosphorylation of the downstream targets of PI3K pathway (AKT, PRAS40, 4EBP1, and S6) and in addition also inhibited the MEK/ ERK pathway [99]. Compensatory activation of the MEK/ERK pathway plays an important role in development of resistance to PI3K inhibitors. Therefore, coinhibition of both the pathways by the same molecule would eliminate signaling by both PI3K pathway and the drug resistance inducing MEK/ERK pathway. In addition to the dual specificity inhibitors that target PI3K and mTOR a unique dual specificity inhibitor, CUDC-907 has entered the clinic (Table 2) [100]. CUDC-907 
combines the inhibitory activity for class I and IIb histone deacetylase (HDAC) enzymes with inhibition of PI3K $\alpha, \beta$ and $\delta$ isoforms [101]. Acetylation of proteins and their deacetylation by HDACs regulate the activity of several cellular proteins in addition to that of the histones. One such protein is HSP90, a chaperone protein. Increase in acetylation in presence of HDACi leads to increase in proteasomal degradation of mutant oncoproteins such as JAK2, KIT and AKT [102]. The loss of mutated oncoproteins will therefore, lead to elimination of the pathogenic clones. Thus CUDC-907 simultaneously targets both the driving oncoprotein and the aberrant PI3K signaling. Since many of the MPNs also carry mutations in proteins that deregulate the epigenome, combining the epigenetic modifying activity with inhibition of signaling holds promise. The complete data is not yet available but the early results indicate that CUDC also targets the microenvironment due to its anti-angiogenic activity [101]. Earlier the emphasis had been on the specificity of the chemical inhibitors. However, the current trends and results from the clinic show emergence of drug resistance due to hyper activation of compensatory pathways when one single pathway is targeted. With the emergence of the concept of 'signaling networks' rather than 'linear pathways', molecules that target different nodes in the network would possibly be more effective in shutting down a 'pathway' rather than targeting a single node.

\section{Combination therapy}

Constitutional toxicities, sub-optimal efficacy at lower doses and frequent development of resistance due to activation of compensatory survival pathways have limited the success with single drug based therapies. In addition the complex molecular heterogeneity usually found in MPNs and a very variable evolutionary trajectory in patients makes it a challenge to target with a single drug. Though MPL and JAK2 mutations would activate the same downstream signaling pathway in PMF patients but have different prognosis in terms of median survival and leukemic transformation [29]. This is likely to be influenced by other mutations and cytogenetic abnormalities. Over the course of the disease distinct clones may evolve with different combinations of mutations. Coexistence of subclones with different combinations of genetic aberrations and drug sensitivities makes it harder to target with a single molecule. Patients with CALR mutation may respond to JAK2 inhibitor but when it is present in combination with mutation in SETBP, the cells are resistant to the same treatment [46]. More such studies are needed to clarify how additional mutations contribute to the sensitivity of the cells to these drugs but it is reasonably clear that no single drug is likely to be successful for any of these MPNs. The treatment strategies will have to be more personalized to account the combination of mutations and presence of sub clones. Co-targeting different pathways either sequentially or concomitantly is likely to be more effective strategy in such a scenario. In order to identify the pathways that work synergistically with the constitutionally active JAK pathway, Choong et al. [103] used a panel of small molecule inhibitors directed against CDK, MEK/ ERK, JNK, p38 MAPK, Raf, PI3K and mTOR in combination with JAK2 inhibitor ruxolitinib. They found significant synergism with mTOR and MEK/ERK inhibitors while inhibitors of other signaling pathways had little or no effect. Interestingly, most potent synergistic effect was observed with pan PI3K inhibitors (ZSTK474 and GDC0941) and PI3K/mTOR dual inhibitor NVPBEZ235. When used in combination they inhibited phosphorylation of STAT3/5 and p70S6 Kinase/S6 ribosomal protein, the targets of the JAK and PI3K pathway [103]. BEZ235 also demonstrated synergism with other JAK2 inhibitors, TG101209 and SAR302503 [97] as well as UO126, inhibitor of MEK/ERK signaling and Obatoclax, inhibitor of Bcl2 family proteins [96]. While the combination of PI3K inhibitor with JAK2 inhibitor did not prolong the survival of mice transplanted with JAK2 $2^{\mathrm{V} 617 \mathrm{~F}}$ cells, there was $70 \%$ and $60 \%$ reduction in spleen weight as compared to the vehicle treated controls and single drug treated groups, respectively [103]. A relief from the symptoms of the disease can improve the quality of life. Similar synergistic effects were observed using RAD001, allosteric or PP242, ATP competitive inhibitors of mTOR in combination with JAK2 inhibitors ruxolitinib or AZD1480 in proliferation and clonogenic assays using mouse and human cells carrying JAK2 ${ }^{\text {V617F }}$ mutation [87]. Interestingly, INCB040093 another p110 $\delta$ inhibitor in phase I trial (Table 2), was ineffective as a single agent in DLBCL cells with activated JAK/STAT signaling pathway but the cells could be sensitized by a combination treatment with JAK1 inhibitor [104]. Upon combining PI3K inhibitor with JAK inhibitor there was little effect on AKT phosphorylation [103] suggesting that alternative pathways can activate AKT and their concomitant suppression may enhance the therapeutic potential. Consistent with this notion, highly synergistic inhibition of proliferation was observed when AKT inhibitor, MK-2206 was combined with ruxolitinib in human cell line with JAK2 ${ }^{\mathrm{V} 617 \mathrm{~F}}$ mutation [90]. In addition to targeting the proliferating myeloid clones, a combination of PI3K inhibitor PX-866 with MEK inhibitor also attenuated lung fibrosis in preclinical models [73] and may benefit MF patients. These results look promising and provide a strong rationale for combining PI3K inhibitor with JAK2 inhibitors in the management of MPNs. However, these pre-clinical studies are based on cells carrying a single mutation (JAK2) and may not 
accurately represent the situation in vivo with multiple mutations in the same clone. Development of in vitro assays with patient samples can overcome this limitation. Development of mice models with complex mutations that more closely mimic the patient mutation profiles are likely to be more informative in pre-clinical evaluations for drug combinations.

\section{Conclusions}

Discovery of the genetic mutations and understanding of the signaling pathways involved the pathogenesis of MPNs has led to the rational development of small molecule inhibitors that target the signaling intermediaries. Identification of novel mutations in CALR in ET and PMF patients with non-mutated JAK2 and MPL is another important step in this field but the mechanistic details of how CALR contributes to the development of MPN remains to be elucidated. Additionally, the molecular drivers of aberrant signaling in Ph-ve MPN patients that do not have mutations in JAK2, MPL, KIT, CALR and CSF3R need to be identified. Though the role of deregulated cytokine signaling has become clearer, the functional significance of mutations in epigenetic regulators that are frequently associated with MPNs is largely unknown. However it is clear that PI3K pathway plays a pivotal role in the pathogenesis of many of these Ph-ve MPNs and holds promise for future informed therapeutic decisions. Though we are still far from finding a cure, the promising results from preclinical and clinical testing indicate that co-targeting of the PI3K pathway along with the tyrosine kinases and/or epigenetic regulators will significantly improve the response and lead to better disease management. Since a large number of inhibitors are already in safety and efficacy trials for solid tumors and other hematological malignancies, transition from lab to the clinic for MPN will be a rapid process. The major challenge with PI3K inhibitors will involve the management of the feedback inhibitory loops which are also likely to be compromised by these inhibitors. With improved understanding of the regulatory mechanisms and crosstalk between different signaling pathways, it may be possible to overcome the resistance due to activation of compensatory pathways. Future progress will involve a more personalized approach and therapeutic strategies based on the presence of specific genetic and molecular abnormalities in MPN patients. Better in vitro and in vivo models that mimic the complexity in the mutations observed in the patients would more accurately predict the efficacy of drugs. Improvements in patient selection and rational combinations targeting multiple pathways that synergize with PI3K signaling module is more likely to be successful in realizing the full potential of this promising class of inhibitors.

\section{Abbreviations}

MPN: myeloproliferative neoplasm; BCR: B cell receptor; ABL1: Abelson tyrosine protein kinase 1; Ph: Philadelphia Chromosome; CML: Chronic myeloid leukemia; JAK2: Janus kinase 2; PI3K: Phosphatidylinositol 3 kinase; PV: Polycythemia vera; ET: Essential thrombocythemia; PMF: Primary myelofibrosis; WHO: World Health Organization; PDGFR: Platelet derived growth factor receptor; FGFR: Fibroblast growth factor receptor; CNL: Chronic neutrophilic leukemia; CEL-NOS: Chronic eosinophilic leukemia not otherwise specified; FDA: Food and drug administration; IL-3: Interleukin 3; IFN- $\gamma$ R2: Interferon gamma receptor 2; MPL: Thrombopoietin receptor (TPO-R); CALR: Calreticulin; AML: Acute myeloid leukemia; MDS: myelodysplastic syndrome; CMML: Chronic myelomonocytic leukemia; STAT5: Signal transducer and activator of transcription 5; KIT: Stem cell factor receptor; CSF3R: Colony-stimulating factor 3 receptor; SETBP1: SET binding protein 1; TKI: Tyrosine kinase inhibitor; AKT: Protein kinase B; mTOR: Mammalian target of rapamycin; PTEN: Phosphatase and tensin homolog; SHIP: SH2-containing inositol phosphatase; TSC: Tuberous sclerosis proteins; CLL: Chronic Lymphocytic Leukemia; BTK: Bruton's tyrosine kinase; ATP: Adenosine triphosphate; PDK1: Phosphoinositide-dependent protein kinase 1; WBC: White blood cells; GSK3: Glycogen synthase kinase 3; MDM2: Mouse double minute 2; BCl2: B-cell lymphoma 2; BAD: BCl-2-associated death promoter protein; MEK: Mitogen-activated protein kinase kinase; ERK: Extracellular signal-regulated kinases; HDACi: Histone deacetylase inhibitor; CDK: Cyclin-dependent kinase; MAPK: Mitogen-activated protein kinase; JNK: c-Jun N-terminal kinase.

\section{Competing interests}

The authors declare that they have no competing interests.

\section{Authors' contributions}

RP and RK drafted the outline. RP wrote the manuscript, generated the tables and figures. RP and RK critically reviewed and approved the final manuscript.

\section{Acknowledgements}

RP is funded by NIH T32DK-07519 and research in RK lab is supported by R01HL077177, R01HL081111, R01CA173852, R01CA134777 and Riley Children's foundation.

\section{Author details}

'Department of Pediatrics, Herman B Wells Center for Pediatric Research, Indiana University School of Medicine, Indianapolis, IN 46202, USA.

${ }^{2}$ Department of Microbiology and Immunology, Indiana University School of Medicine, Indianapolis, IN 46202, USA. ${ }^{3}$ Department of Medical and Molecular Genetics, Indiana University School of Medicine, Indianapolis, IN 46202, USA. ${ }^{4}$ Department of Molecular Biology and Biochemistry, Indiana University School of Medicine, Indianapolis, IN 46202, USA.

Received: 4 March 2015 Accepted: 18 May 2015

Published online: 11 June 2015

\section{References}

1. Swerdlow SH. WHO classification of tumours of haematopoietic and lymphoid tissues. In: World Health Organization, editor. International Agency for Research on Cancer. 4th ed. Lyon, France: International Agency for Research on Cancer; 2008.

2. Vardiman JW, Thiele J, Arber DA, Brunning RD, Borowitz MJ, Porwit A, et al. The 2008 revision of the World Health Organization (WHO) classification of myeloid neoplasms and acute leukemia: rationale and important changes. Blood. 2009;114:937-51.

3. Sinclair A, Latif AL, Holyoake TL. Targeting survival pathways in chronic myeloid leukaemia stem cells. Br J Pharmacol. 2013;169:1693-707.

4. Evangelisti C, Evangelisti C, Bressanin D, Buontempo F, Chiarini F, Lonetti A, et al. Targeting phosphatidylinositol 3-kinase signaling in acute myelogenous leukemia. Expert Opin Ther Targets. 2013;17:921-36.

5. Mehta J, Wang H, lqbal SU, Mesa R. Epidemiology of myeloproliferative neoplasms in the United States. Leuk Lymphoma. 2014;55:595-600.

6. Wolf D, Rudzki J, Gastl G. Current treatment concepts of Philadelphia-negative MPN. Curr Cancer Drug Targets. 2011;11:44-55.

7. Sohn SK. Is a cure for CML without allogeneic stem cell transplantation around the corner? Blood Res. 2014;49:141-3. 
8. Freireich EJ, Wiernik PH, Steensma DP. The leukemias: a half-century of discovery. J Clin Oncol. 2014;32:3463-9.

9. Levine RL, Wadleigh M, Cools J, Ebert BL, Wernig G, Huntly BJ, et al, Activating mutation in the tyrosine kinase JAK2 in polycythemia vera, essential thrombocythemia, and myeloid metaplasia with myelofibrosis. Cancer Cell. 2005;7:387-97.

10. Baxter EJ, Scott LM, Campbell PJ, East C, Fourouclas N, Swanton S, et al. Cancer Genome Project. Cancer Genome Project. Acquired mutation of the tyrosine kinase JAK2 in human myeloproliferative disorders. Lancet. 2005:365:1054-61.

11. James C, Ugo V, Le Couédic JP, Staerk J, Delhommeau F, Lacout C, et al. A unique clonal JAK2 mutation leading to constitutive signalling causes polycythaemia vera. Nature. 2005;434:1144-8.

12. Milosevic JD, Kralovics R. Genetic and epigenetic alterations of myeloproliferative disorders. Int J Hematol. 2013;97:183-97.

13. Kim E, Abdel-Wahab O. Focus on the epigenome in the myeloproliferative neoplasms. Hematology Am Soc Hematol Educ Program 2013;2013:538-544. doi:10.1182/asheducation-2013.1.538.

14. Delhommeau F, Dupont S, Tonetti C, Massé A, Godin I, Le Couedic JP, et al. Evidence that the JAK2 G1849T (V617F) mutation occurs in a lymphomyeloid progenitor in polycythemia vera and idiopathic myelofibrosis. Blood. 2007;109:71-7.

15. James C, Mazurier F, Dupont S, Chaligne R, Lamrissi-Garcia I, Tulliez M, et al. The hematopoietic stem cell compartment of JAK2V617F-positive myeloproliferative disorders is a reflection of disease heterogeneity. Blood. 2008;112:2429-38.

16. Klampfl T, Harutyunyan A, Berg T, Gisslinger B, Schalling M, Bagienski K, et al. Genome integrity of myeloproliferative neoplasms in chronic phase and during disease progression. Blood. 2011;118:167-76.

17. Theocharides A, Boissinot M, Girodon F, Garand R, Teo SS, Lippert E, et al. Leukemic blasts in transformed JAK2-V617F-positive myeloproliferative disorders are frequently negative for the JAK2-V617F mutation. Blood. 2007;110:375-9.

18. Beer PA, Delhommeau F, LeCouédic JP, Dawson MA, Chen E, Bareford D, et al. Two routes to leukemic transformation after a JAK2 mutation-positive myeloproliferative neoplasm. Blood. 2010;115:2891-900.

19. Harutyunyan A, Klampfl T, Cazzola M, Kralovics R. p53 lesions in leukemic transformation. N Engl J Med. 2011;364:488-90.

20. Carneiro BA, Kaplan JB, Altman JK, Giles FJ, Platanias LC. Targeting mTOR signaling pathways and related negative feedback loops for the treatment of acute myeloid leukemia. Cancer Biol Ther. 2015;24.

21. Fransecky L, Mochmann LH, Baldus CD. Outlook on PI3K/AKT/mTOR inhibition in acute leukemia. Molecular Cellular Therapies. 2015;3:2.

22. Babon JJ, Lucet IS, Murphy JM, Nicola NA, Varghese LN. The molecular regulation of Janus kinase (JAK) activation. Biochem J. 2014;1462:1-13.

23. Chen E, Beer PA, Godfrey AL, Ortmann CA, Li J, Costa-Pereira AP, et al. Distinct clinical phenotypes associated with JAK2V617F reflect differential STAT1 signaling. Cancer Cell. 2010;18:524-35.

24. Pardanani AD, Levine RL, Lasho T, Pikman Y, Mesa RA, Wadleigh M, et al. MPL515 mutations in myeloproliferative and other myeloid disorders: a study of 1182 patients. Blood. 2006;108:3472-6.

25. Scott LM, Tong W, Levine RL, Scott MA, Beer PA, Stratton MR, et al. JAK2 exon 12 mutations in polycythemia vera and idiopathic erythrocytosis. N Engl J Med. 2007;356:459-68.

26. Klampfl T, Gisslinger $H$, Harutyunyan AS, Nivarthi H, Rumi E, Milosevic JD, et al. Somatic mutations of calreticulin in myeloproliferative neoplasms. N Engl J Med. 2013;369:2379-90.

27. Tefferi A, Guglielmelli P, Larson DR, Finke C, Wassie EA, Pieri L, et al. Long-term survival and blast transformation in molecularly annotated essential thrombocythemia, polycythemia vera, and myelofibrosis. Blood. 2014;124:2507-13.

28. Tefferi A, Lasho TL, Finke C, Belachew AA, Wassie EA, Ketterling RP, et al. Type 1 vs type 2 calreticulin mutations in primary myelofibrosis: differences in phenotype and prognostic impact. Leukemia. 2014;28:1568-70.

29. Tefferi A, Lasho TL, Finke CM, Knudson RA, Ketterling R, Hanson CH, et al. CALR VS JAK2 vs MPL-mutated or triple-negative myelofibrosis: clinical, cytogenetic and molecular comparisons. Leukemia. 2014;28:1472-7.

30. Nagata H, Worobec AS, Oh CK, Chowdhury BA, Tannenbaum S, Suzuki Y, et al. Identification of a point mutation in the catalytic domain of the protooncogene c-kit in peripheral blood mononuclear cells of patients who have mastocytosis with an associated hematologic disorder. Proc Natl Acad Sci U S A. 1995;92:10560-4.
31. Longley BJ, Tyrrell L, Lu SZ, Langley K, Ding TG, Duffy T, et al. Somatic C-KIT activating mutation in urticaria pigmentosa and aggressive mastocytosis: establishment of clonality in a human mast cell neoplasm. Nat Genet. 1996;12:312-4

32. Foster R, Byrnes E, Meldrum C, Griffith R, Ross G, Upjohn E, et al. Association of paediatric mastocytosis with a polymorphism resulting in an amino acid substitution (M541L) in the transmembrane domain of c-KIT. Br J Dermatol. 2008;159:1160-9.

33. Ma P, Mali RS, Martin H, Ramdas B, Sims E, Kapur R. Role of intracellular tyrosines in activating KIT-induced myeloproliferative disease. Leukemia. 2012;26:1499-506.

34. Mali RS, Ramdas B, Ma P, Shi J, Munugalavadla V, Sims E, et al. Rho kinase regulates the survival and transformation of cells bearing oncogenic forms of KIT, FLT3, and BCR-ABL. Cancer Cell. 2011;20:357-69.

35. Frost MJ, Ferrao PT, Hughes TP, Ashman LK. Juxtamembrane mutant V560GKit is more sensitive to Imatinib (STI571) compared with wild-type c-kit whereas the kinase domain mutant D816VKit is resistant. Mol Cancer Ther. 2002;1:1115-24.

36. Ma Y, Zeng S, Metcalfe DD, Akin C, Dimitrijevic S, Butterfield JH, et al. The c-KIT mutation causing human mastocytosis is resistant to STI571 and other KIT kinase inhibitors; kinases with enzymatic site mutations show different inhibitor sensitivity profiles than wild-type kinases and those with regulatory-type mutations. Blood. 2002;99:1741-4.

37. Schittenhelm MM, Shiraga S, Schroeder A, Corbin AS, Griffith D, Lee FY, et al. Dasatinib (BMS-354825), a dual SRC/ABL kinase inhibitor, inhibits the kinase activity of wild-type, juxtamembrane, and activation loop mutant KIT isoforms associated with human malignancies. Cancer Res. 2006;66:473-81.

38. Pardanani A. Systemic mastocytosis in adults: 2011 update on diagnosis, risk stratification, and management. Am J Hematol. 2011;86:362-71.

39. Mali RS, Ma P, Zeng LF, Martin H, Ramdas B, He Y, et al. Role of SHP2 phosphatase in KTT-induced transformation: identification of SHP2 as a druggable target in diseases involving oncogenic KIT. Blood. 2012;120:2669-78.

40. Martin H, Mali RS, Ma P, Chatterjee A, Ramdas B, Sims E, et al. Pak and Rac GTPases promote oncogenic KIT-induced neoplasms. J Clin Invest. 2013;123:4449-63.

41. Chatterjee A, Ghosh J, Ramdas B, Mali RS, Martin H, Kobayashi M, et al. Regulation of Stat 5 by FAK and PAK1 in Oncogenic FLT3- and KIT-Driven Leukemogenesis. Cell Rep. 2014;9:1333-48.

42. Maxson JE, Gotlib J, Pollyea DA, Fleischman AG, Agarwal A, Eide CA, et al. Oncogenic CSF3R mutations in chronic neutrophilic leukemia and atypical CML. N Engl J Med. 2013;368:1781-90.

43. Pardanani A, Lasho TL, Laborde RR, Elliott M, Hanson CA, Knudson RA, et al. CSF3R T6181 is a highly prevalent and specific mutation in chronic neutrophilic leukemia. Leukemia. 2013;27:1870-3.

44. Cui Y, Li B, Gale RP, Jiang Q, Xu Z, Qin T, et al. CSF3R, SETBP1 and CALR mutations in chronic neutrophilic leukemia. J Hematol Oncol. 2014;7:77.

45. Fleischman AG, Maxson JE, Luty SB, Agarwal A, Royer LR, Abel ML, et al. The CSF3R T618I mutation causes a lethal neutrophilic neoplasia in mice that is responsive to therapeutic JAK inhibition. Blood. 2013;122:3628-31.

46. Lasho TL, Mims A, Elliott MA, Finke C, Pardanani A, Tefferi A. Chronic neutrophilic leukemia with concurrent CSF3R and SETBP1 mutations: single colony clonality studies, in vitro sensitivity to JAK inhibitors and lack of treatment response to ruxolitinib. Leukemia. 2014;28:1363-5.

47. Helbig G, Soja A, Bartkowska-Chrobok A, Kyrcz-Krzemień S. Chronic eosinophilic leukemia-not otherwise specified has a poor prognosis with unresponsiveness to conventional treatment and high risk of acute transformation. Am J Hematol. 2012;87:643-5.

48. Iurlo A, Gianelli U, Beghini A, Spinelli O, Orofino N, Lazzaroni F, et al. Identification of kit (M541L) somatic mutation in chronic eosinophilic leukemia, not otherwise specified and its implication in low-dose imatinib response. Oncotarget. 2014;:5:4665-70.

49. Verstovsek S, Kantarjian H, Mesa RA, Pardanani AD, Cortes-Franco J, Thomas DA, et al. Safety and efficacy of INCB018424, a JAK1 and JAK2 inhibitor, in myelofibrosis. N Engl J Med. 2010;363:1117-27.

50. Harrison C, Kiladjian JJ, Al-Ali HK, Gisslinger H, Waltzman R, Stalbovskaya V, et al. JAK inhibition with ruxolitinib versus best available therapy for myelofibrosis. N Engl J Med. 2012;366:787-98.

51. Pardanani A, Vannucchi AM, Passamonti F, Cervantes F, Barbui T, Tefferi A. JAK inhibitor therapy for myelofibrosis: critical assessment of value and limitations. Leukemia. 2011;25:218-25.

52. Tefferi A. JAK inhibitors for myeloproliferative neoplasms: clarifying facts from myths. Blood. 2012;119:2721-30. 
53. Sanofi discontinues clinical development of investigational JAK2 agent Fedratinib (SAR302503). [http://en.sanofi.com/Images/34935_20131118_ JAK-2-FEDRATINIB_en.pdf]

54. Plimack ER, Lorusso PM, McCoon P, Tang W, Krebs AD, Curt G, et al. AZD1480: a phase I study of a novel JAK2 inhibitor in solid tumors. Oncologist. 2013;18:819-20.

55. Verstovsek S, Tam CS, Wadleigh M, Sokol L, Smith CC, Bui LA, et al. Phase I evaluation of XL019, an oral, potent, and selective JAK2 inhibitor. Leuk Res. 2014;38:316-22.

56. Sonbol MB, Firwana B, Zarzour A, Morad M, Rana V, Tiu RV. Comprehensive review of JAK inhibitors in myeloproliferative neoplasms. Ther Adv Hematol. 2013;4:15-35.

57. Stein BL, Swords R, Hochhaus A, Giles F. Novel myelofibrosis treatment strategies: potential partners for combination therapies. Leukemia. 2014;28:2139-47.

58. Fruman DA, Meyers RE, Cantley LC. Phosphoinositide kinases. Annu Rev Biochem. 1998;67:481-507.

59. Jean S, Kiger AA. Classes of phosphoinositide 3-kinases at a glance. J Cell Sci. 2014;127:923-8.

60. Klempner SJ, Myers AP, Cantley LC. What a tangled web we weave: emerging resistance mechanisms to inhibition of the phosphoinositide 3-kinase pathway. Cancer Discov. 2013;3:1345-54.

61. Rozengurt E, Soares HP, Sinnet-Smith J. Suppression of feedback loops mediated by PI3K/mTOR induces multiple over activation of compensatory pathways: an unintended consequence leading to drug resistance. Mol Cancer Ther. 2014;13:2477-88.

62. Fruman DA, Rommel C. PI3K and cancer: lessons, challenges and opportunities. Nat Rev Drug Discov. 2014;13:140-56.

63. Polivka Jr J, Janku F. Molecular targets for cancer therapy in the PI3K/AKT/ mTOR pathway. Pharmacol Ther. 2014;142:164-75.

64. Grimwade LF, Happerfield L, Tristram C, McIntosh G, Rees M, Bench AJ, et al. Phospho-STAT5 and phospho-Akt expression in chronic myeloproliferative neoplasms. Br J Haematol. 2009;147:495-506.

65. Munugalavadla V, Sims EC, Chan RJ, Lenz SD, Kapur R. Requirement for p85alpha regulatory subunit of class IA PI3K in myeloproliferative disease driven by an activation loop mutant of KIT. Exp Hematol. 2008;36:301-8.

66. Krishnan S, Mali RS, Ramdas B, Sims E, Ma P, Ghosh J, et al. p85 $\beta$ regulatory subunit of class IA PI3 kinase negatively regulates mast cell growth, maturation, and leukemogenesis. Blood. 2012;119:3951-61.

67. Goodwin CB, Li XJ, Mali RS, Chan G, Kang M, Liu Z, et al. PI3K p1108 uniquely promotes gain-of-function Shp2-induced GM-CSF hypersensitivity in a model of JMML. Blood. 2014;123:2838-42.

68. Quentmeier H, Eberth S, Romani J, Zaborski M, Drexler HG. BCR-ABL1independent PI3Kinase activation causing imatinib-resistance. J Hematol Oncol. 2011:4:6.

69. Nishioka C, Ikezoe T, Yang J, Yokoyama A. Long-term exposure of leukemia cells to multi-targeted tyrosine kinase inhibitor induces activations of AKT, ERK and STAT5 signaling via epigenetic silencing of the PTEN gene. Leukemia. 2010;24:1631-40.

70. The Clinical Trial Registry Database. [https://clinicaltrials.gov].

71. Hong DS, Bowles DW, Falchook GS, Messersmith WA, George GC, O'Bryant CL, et al. A multicenter phase I trial of PX-866, an oral irreversible phosphatidylinositol 3-kinase inhibitor, in patients with advanced solid tumors. Clin Cancer Res. 2012;18:4173-82

72. Le Cras TD, Korfhagen TR, Davidson C, Schmidt S, Fenchel M, Ikegami M, et al. Inhibition of PI3K by PX-866 prevents transforming growth factor-alpha-induced pulmonary fibrosis. Am J Pathol. 2010;176:679-86.

73. Madala SK, Edukulla R, Phatak M, Schmidt S, Davidson C, Acciani TH, et al. Dual targeting of MEK and PI3K pathways attenuates established and progressive pulmonary fibrosis. PLoS One. 2014;9:e86536.

74. Rosich L, Saborit-Villarroya I, López-Guerra M, Xargay-Torrent S, Montraveta A, Aymerich $M$, et al. The phosphatidylinositol-3-kinase inhibitor NVP-BKM120 overcomes resistance signals derived from microenvironment by regulating the Akt/FoxO3a/Bim axis in chronic lymphocytic leukemia cells. Haematologica. 2013;98:1739-47.

75. Lonetti A, Antunes IL, Chiarini F, Orsini E, Buontempo F, Ricci F, et al. Activity of the pan-class I phosphoinositide 3-kinase inhibitor NVP-BKM120 in T-cell acute lymphoblastic leukemia. Leukemia. 2014;28:1196-206.

76. Brown JR, Byrd JC, Coutre SE, Benson DM, Flinn IW, Wagner-Johnston ND, et al. Idelalisib, an inhibitor of phosphatidylinositol 3-kinase p1108, for relapsed/refractory chronic lymphocytic leukemia. Blood. 2014;123:3390-7.
77. Furman RR, Sharman JP, Coutre SE, Cheson BD, Pagel JM, Hillmen P, et al. Idelalisib and rituximab in relapsed chronic lymphocytic leukemia. N Engl J Med. 2014;370:997-1007.

78. Dubovsky JA, Chappell DL, Harrington BK, Agrawal K, Andritsos LA, Flynn $J M$, et al. Lymphocyte cytosolic protein 1 is a chronic lymphocytic leukemia membrane-associated antigen critical to niche homing. Blood. 2013;122:3308-16.

79. Fiorcari S, Brown WS, McIntyre BW, Estrov Z, Maffei R, O'Brien S, et al. The PI3-kinase delta inhibitor idelalisib (GS-1101) targets integrin-mediated adhesion of chronic lymphocytic leukemia (CLL) cell to endothelial and marrow stromal cells. PLoS One. 2013;8, e83830.

80. Dong S, Guinn D, Dubovsky JA, Zhong Y, Lehman A, Kutok J, et al. IPI-145 antagonizes intrinsic and extrinsic survival signals in chronic lymphocytic leukemia cells. Blood. 2014;124:3583-6.

81. Winkler DG, Faia KL, DiNitto JP, Ali JA, White KF, Brophy EE, et al. PI3K- $\delta$ and PI3K- $y$ inhibition by IPI-145 abrogates immune responses and suppresses activity in autoimmune and inflammatory disease models. Chem Biol. 2013;20:1364-74

82. Chiarini F, Evangelisti C, McCubrey JA, Martelli AM. Current treatment strategies for inhibiting mTOR in cancer. Trends Pharmacol Sci 2014. doi:10.1016/j.tips.2014.11.004.

83. Smrz D, Kim MS, Zhang S, Mock BA, Smrzová S, DuBois W, et al. mTORC1 and $\mathrm{MTORC2}$ differentially regulate homeostasis of neoplastic and non-neoplastic human mast cells. Blood. 2011;118:6803-13.

84. Gabillot-Carré M, Lepelletier Y, Humbert M, de Sepuvelda P, Hamouda NB, Zappulla JP, et al. Rapamycin inhibits growth and survival of D816V-mutated c-kit mast cells. Blood. 2006;108:1065-72

85. Parikh SA, Kantarjian HM, Richie MA, Cortes JE, Verstovsek S. Experience with everolimus (RAD001), an oral mammalian target of rapamycin inhibitor, in patients with systemic mastocytosis. Leuk Lymphoma. 2010;51:269-74.

86. Guglielmelli P, Barosi G, Rambaldi A, Marchioli R, Masciulli A, Tozzi L, et al. AIRC-Gruppo Italiano Malattie Mieloproliferative (AGIMM) investigators: Safety and efficacy of everolimus, a mTOR inhibitor, as single agent in a phase 1/2 study in patients with myelofibrosis. Blood. 2011;118:2069-76.

87. Bogani C, Bartalucci N, Martinelli S, Tozzi L, Guglielmelli P, Bosi A, et al. Associazione Italiana per la Ricerca sul Cancro AGIMM Gruppo Italiano Malattie Mieloproliferative: MTOR inhibitors alone and in combination with JAK2 inhibitors effectively inhibit cells of myeloproliferative neoplasms. PLOS One. 2013;8, e54826.

88. Choo AY, Yoon SO, Kim SG, Roux PP, Blenis J. Rapamycin differentially inhibits S6Ks and 4E-BP1 to mediate cell-type-specific repression of mRNA translation. Proc Natl Acad Sci U S A. 2008;105:17414-9.

89. Rodrik-Outmezguine VS, Chandarlapaty S, Pagano NC, Poulikakos PI, Scaltriti M, Moskatel E, et al. mTOR kinase inhibition causes feedback-dependent biphasic regulation of AKT signaling. Cancer Discov. 2011;1:248-59.

90. Khan I, Huang Z, Wen Q, Stankiewicz MJ, Gilles L, Goldenson B, et al. AKT is a therapeutic target in myeloproliferative neoplasms. Leukemia. 2013;27:1882-90.

91. Rosen DB, Harrington KH, Cordeiro JA, Leung LY, Putta S, Lacayo N, et al. AKT signaling as a novel factor associated with in vitro resistance of human AML to gemtuzumab ozogamicin. PLoS One. 2013;8, e53518.

92. Sato S, Fujita N, Tsuruo T. Interference with PDK1-Akt survival signaling pathway by UCN-01 (7-hydroxystaurosporine). Oncogene. 2002;21:1727-38.

93. Hilgard P, Klenner T, Stekar J, Nössner G, Kutscher B, Engel J. D-21266, a new heterocyclic alkylphospholipid with antitumour activity. Eur J Cancer. 1997;33:442-6

94. Gojo I, Perl A, Luger S, Baer MR, Norsworthy KJ, Bauer KS, et al. Phase I study of UCN-01 and perifosine in patients with relapsed and refractory acute leukemias and high-risk myelodysplastic syndrome. Invest New Drugs. 2013;31:1217-27.

95. Blatt K, Herrmann H, Mirkina I, Hadzijusufovic E, Peter B, Strommer S, et al. The PI3-kinase/mTOR-targeting drug NVP-BEZ235 inhibits growth and IgE-dependent activation of human mast cells and basophils. PLoS One. 2012;7, e29925.

96. Buet D, Gallais I, Lauret E, Denis N, Lombard B, Guillonneau F, et al. Cotargeting signaling pathways driving survival and cell cycle circumvents resistance to Kit inhibitors in leukemia. Blood. 2012;119:4228-41.

97. Fiskus W, Verstovsek S, Manshouri T, Smith JE, Peth K, Abhyankar S, et al. Dual PI3K/AKT/mTOR inhibitor BEZ235 synergistically enhances the activity of JAK2 inhibitor against cultured and primary human myeloproliferative neoplasm cells. Mol Cancer Ther. 2013;12:577-88. 
98. Yoda A, Adelmant G, Tamburini J, Chapuy B, Shindoh N, Yoda Y, et al. Mutations in $\mathrm{G}$ protein $\beta$ subunits promote transformation and kinase inhibitor resistance. Nat Med 2014. doi:10.1038/nm.3751.

99. Shapiro Gl, Rodon J, Bedell C, Kwak EL, Baselga J, Braña I, et al. Phase I safety, pharmacokinetic, and pharmacodynamic study of SAR245408 (XL147), an oral pan-class I PI3K inhibitor, in patients with advanced solid tumors. Clin Cancer Res. 2014;20:233-45.

100. Qian C, Lai CJ, Bao R, Wang DG, Wang J, Xu GX, et al. Cancer network disruption by a single molecule inhibitor targeting both histone deacetylase activity and phosphatidylinositol 3-kinase signaling. Clin Cancer Res. 2012;18:4104-13

101. Ma AW, Atoyan R, Younes A, Flinn IW, Oki Y, Copeland A, et al. Abstract 1879: Dual function HDAC and PI3K inhibitor, CUDC-907 affects cancer cells and the tumor microenvironment in hematological malignancies. Cancer Res. 2014;74:1879.

102. Mithraprabhu S, Grigoriadis G, Khong T, Spencer A. Deactylase inhibition in myeloproliferative neoplasms. Invest New Drugs. 2010;28 Suppl 1:S50-7.

103. Choong ML, Pecquet C, Pendharkar V, Diaconu CC, Yong JW, Tai SJ, et al. Combination treatment for myeloproliferative neoplasms using JAK and pan-class I PI3K inhibitors. J Cell Mol Med. 2013;17:1397-409.

104. Liu X, Favata M, Li J, Shin N, Wang KH, Wang Q, et al. Abstract 4207: JAK inhibition reverses IL10-mediated resistance to $B$ cell receptor $(B C R)$ pathway inhibition in DLBCL. Cancer Res 2014 74. doi:10.1158/1538-7445.AM2014-4207.

\section{Submit your next manuscript to BioMed Central and take full advantage of:}

- Convenient online submission

- Thorough peer review

- No space constraints or color figure charges

- Immediate publication on acceptance

- Inclusion in PubMed, CAS, Scopus and Google Scholar

- Research which is freely available for redistribution 